\title{
A new, mild and high yielding protocol for the preparation of nitriles from aldehydes using iodosobenzene diacetate in aqueous ammonia
}

\author{
Seema Bag, Nilesh R. Tawari, and Mariam S. Degani* \\ Institute of Chemical Technology, University under Section 3 of the UGC Act 1956, Nathalal \\ Parikh Marg, Matunga, Mumbai-400019, India \\ E-mail: ms.degani@ictmumbai.edu.in.
}

\begin{abstract}
A new, mild and high yielding protocol was developed for the transformation of aldehydes into nitriles using iodosobenzene diacetate (IBD) in aqueous ammonia under mild reaction conditions at room temperature.
\end{abstract}

Keywords: Aldehyde, nitrile, iodosobenzene diacetate

\section{Introduction}

Transformation of aldehydes into nitriles is of prime importance because of the versatility of nitriles as starting materials for the synthesis of various bioactive molecules of pharmaceutical interest. These are also used for the synthesis of nitrogen-containing functional moieties like triazines, thiazoles, 2-oxazolines, tetrazoles, imidazoles, triazoles which possess a broad spectrum of biological activities. Moreover, the nitriles can be converted to various functional groups such as amides, carboxylic acids, amines, ketones, and esters. ${ }^{1-3}$

During the course of our research related to the synthesis of novel triazine analogs as antiinfective agents, we were required to synthesize nitriles from their corresponding aldehydes. Therefore, we re-examined various methods reported in literature for the preparation of nitriles from aldehydes. Principally, nitrile can be obtained either by dehydration of aldoximes or by oxidation of aldimines prepared from the corresponding aldehydes under various conditions. Also reagents ${ }^{4-8}$ such as trimethylsilyl azide, ${ }^{9}$ triazidochlorosilane, ${ }^{10}$ sodium azide and aluminium chloride $^{11}$ can be used. However, the above mentioned methods suffer from various drawbacks such as long reaction times, low yields, drastic reaction conditions, use of hazardous, expensive and easily inaccessible reagents and some of them also involve tedious workup procedures. ${ }^{12}$ Also, several methods are reported using various reagents in combination with ammonia e.g $\mathrm{NH}_{3}, \mathrm{H}_{2} \mathrm{O}_{2} ;{ }^{13} \mathrm{NH}_{3} / \mathrm{I}_{2}$ in THF-water; ${ }^{14-16} \mathrm{NH}_{3} / \mathrm{NBS}$ in water. ${ }^{17}$ 
This type of direct conversion has proved very attractive to medicinal chemists for synthesizing new chemical entities. Despite all these reported methods, there is still scope for alternative novel reagent systems for this useful functional group transformation.

Hypervalent iodine reagents are extensively used for various transformations in organic synthesis because of their low toxicity, ease of handling, and high reactivity. Recently, hypervalent iodine reagents such as $\mathrm{IBX}^{18}$ and $\mathrm{NaICl}_{2}{ }^{19}$ have also been explored for this conversion in combination with aqueous ammonia. These reagents are environmentally benign and are also known for their selective, efficient and mild properties as oxidizing agents. ${ }^{20-23}$

We have developed a mild protocol for the above functional group transformation using hypervalent iodine reagent, iodosobenzene diacetate (IBD) in aqueous ammonia (Scheme 1).

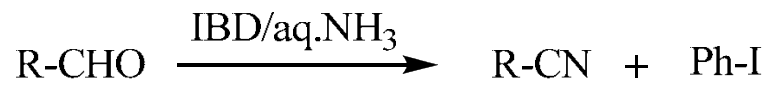

r.t.

Scheme 1. Synthesis of nitrile from corresponding aldehyde.

To the best of our knowledge there is no report in the literature where IBD is used for such a transformation.

\section{Results and Discussion}

In our initial studies, $p$-methylbenzaldehyde was treated with aqueous ammonia at room temperature $\left(25^{\circ} \mathrm{C}\right)$ followed by addition of IBD. The reaction was completed within 3 hours as seen by TLC. Workup of the reaction followed by column chromatography gave the desired ptolylnitrile in $90 \%$ yields with almost quantitative recovery of iodobenzene. Reaction protocols developed in aqueous media made the workup procedure simple and environmentally safe. Various aliphatic/aromatic aldehydes were subjected to these reaction conditions and gave moderate to high yields of the corresponding nitriles as shown in Table 1. Literature survey revealed that entry numbers $\mathbf{1 2}$ and $\mathbf{1 4}$ (Table 1) are novel molecules. 
Table 1. Conversion of aldehydes to nitriles using IBD/aqueous ammonia

Entry $^{24}$

iStructures were confirmed from their spectral data (NMR and IR).

ii Isolated yield.

Many aromatic substituted/ unsubstituted aldehydes underwent the reaction smoothly. Aldehydes with electron withdrawing groups gave lower yields and required longer reaction times (entry 6 and 9, Table 1). The aliphatic aldehyde (entry 10, Table 1) also took longer reaction time for completion. Heteroaromatic aldehyde (entry 7, Table 1) underwent transformation smoothly giving high yields. Cinnamaldehyde (entry 8, Table 1) gave corresponding cinnamonitrile in $80 \%$ yield in 5 hours at room temperature. Small amount of 
THF was added to increase the solubility of starting material in order to ensure complete conversion.

We speculate that the reaction using our developed protocol proceeds via oxidation of aldimines using IBD. The reaction of aldehyde with ammonia results in the formation of aldimine. Similar to the reaction with other hypervalent iodine compounds, aldimine get oxidized to nitrile by the IBD as shown in Scheme 2. The formation of iodobenzene gave an added advantage to the developed protocol because it is used as a starting material in the synthesis of IBD, thus making the developed protocol more economical. The driving force for this transformation could be the reduction of I (III) to the more stable I (I) in the reaction mixture leading to the formation of nitrile which is more stable than its intermediate aldimine.

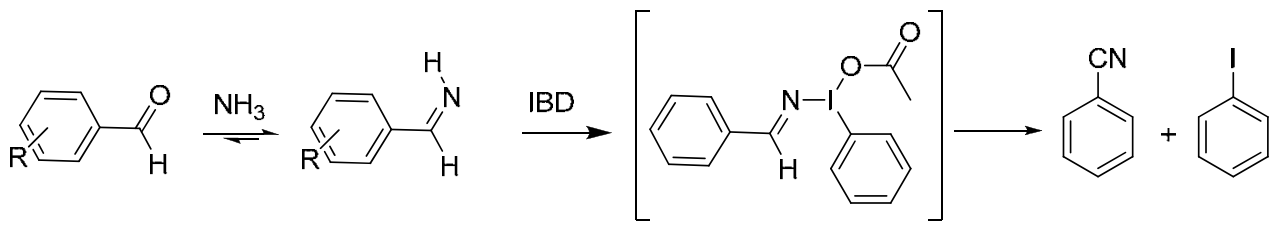

Scheme 2. Plausible reaction pathway for the conversion of aldehyde to nitrile using IBD.

\section{Conclusions}

In conclusion, a novel method has been developed for the direct conversion of aldehydes to the corresponding nitriles using IBD in combination with aqueous ammonia at room temperature. The method gave excellent yields for the various aliphatic and aromatic aldehydes. Thus we can say that the method is simple, efficient, environmentally safe and economical.

\section{Experimental Section}

General. All melting points (m.p.) were recorded on Thermomik Compbell electronics, having oil-heating system and were uncorrected. FTIR spectra were recorded on "Buck scientific infrared spectroscopy M500 spectrophotometer". All the NMR spectra were recorded on Bruker DMX-500 spectrometer operating at $500 \mathrm{MHz}$ with $\mathrm{CDCl}_{3}$ as solvent using tetramethyl silane (TMS) as internal reference: $\mathrm{d}=$ doublet, $\mathrm{t}=$ triplet, $\mathrm{q}=$ quartet.

\section{Typical experimental procedure}

Iodosobenzene diacetate $(1.1 \mathrm{mmole})$ was added to the stirred solution of aldehyde $(1 \mathrm{mmole})$ in THF $(2 \mathrm{ml})$ and aqueous ammonia $(10 \mathrm{ml}$ of a $28-30 \%$ solution, Sp. gravity $=0.89)$. Within 2 minutes of addition of the reagent, the free flowing white colored reagent turned to fluffy and yellow. Reaction was exothermic and the reaction mixture turned dark red. Within few minutes 
of stirring at room temperature, separation of two layers was observed. Stirring was continued at room temperature for 4-9 hours. After completion of reaction (monitored by TLC), the reaction mixture was diluted with water and extracted with DCM $(3 \times 10 \mathrm{ml})$. The organic layer was washed with saturated solution of sodium bisulphite and followed by saturated solution of sodium bicarbonate, water and brine. The organic layer was dried over anhydrous sodium sulphate. Column purification (5\% ethylacetate: hexanes) gave the desired product along with the recovery of iodobenzene in almost quantitative yields.

4-(1-(4-Chlorophenyl)ethoxy)benzonitrile (Entry 12). IR (KBr) 3075, 2979, 2904, 2225, 1606, 1570, 1507, 1451, 1404, 1374, 1300, 1253, 1174, 1122, 1096, 1074, 1012, 931, 839, 821, 805, $720 \mathrm{~cm}^{-1} ;{ }^{1} \mathrm{H}-\mathrm{NMR}\left(\mathrm{CDCl}_{3}, 500 \mathrm{MHz}\right): \delta 1.63-1.65\left(\mathrm{~d}, 3 \mathrm{H},-\mathrm{CH}_{3}, J=7 \mathrm{MHz}\right), 5.31-5.35$ (q, 2H, $-\mathrm{CH}, J=6.5 \mathrm{MHz}$ ), 6.86-6.88 (d, 2H, Ar H, $J=9 \mathrm{MHz}), 7.26-7.28$ (d, 2H, Ar H, $J=9 \mathrm{MHz}$ ), 7.31-7.33 (d, 2H, Ar H, $J=9 \mathrm{MHz}), 7.48-7.50$ (d, 2H, Ar H, J = 9 MHz); ${ }^{13} \mathrm{C}-\mathrm{NMR}\left(\mathrm{CDCl}_{3}, 700\right.$ $\mathrm{MHz}): \delta$ 24.4469, 76.0361, 104.2687, 116.5574, 119.2314, 126.9474, 129.2593, 133.8479, $134.0535,140.5670,161.1300$

4-(1-(4-Bromophenyl)ethoxy)benzonitrile (Entry 14). IR (KBr): 3071, 2978, 2210, 1607, 1503, 1296, 1249, 1171, 1068, 1005, 933, 839, $818 \mathrm{~cm}^{-1} ;{ }^{1} \mathrm{H}-\mathrm{NMR}\left(\mathrm{CDCl}_{3}, 500 \mathrm{MHz}\right): \delta 1.63-$ $1.64\left(\mathrm{~d}, 3 \mathrm{H},-\mathrm{CH}_{3}, J=6.5 \mathrm{MHz}\right), 5.29-5.33$ (q, 2H, -CH, $\left.J=6.5 \mathrm{MHz}\right), 6.86-6.88$ (d, 2H, Ar H, $J$

$=8.5 \mathrm{MHz}), 7.20-7.22(\mathrm{~d}, 2 \mathrm{H}, \mathrm{Ar} \mathrm{H}, J=8 \mathrm{MHz}), 7.47-7.50(\mathrm{t}, 4 \mathrm{H}, \mathrm{Ar} \mathrm{H}, J=8.5 \mathrm{MHz}) ;{ }^{13} \mathrm{C}-$ NMR $\left(\mathrm{CDCl}_{3}, 700 \mathrm{MHz}\right): \delta 24.4,76.07,104.28,116.55,119.23,121.92,127.28,132.21,134.06$, $141.10,161.11$

\section{Acknowledgements}

Seema Bag is thankful to University Grand Commission (UGC), India and Nilesh R. Tawari is thankful to Department of Biotechnology (DBT), India for financial support.

\section{References}

1. Mowry, D. T. Chem. Rev. 1948, 42, 189.

2. Friedrich, K.; Wallensfels K. In The Chemistry of Cyano Group; Rappoport, Z., Ed.; WileyInterscience: New York, 1970.

3. North, M. In Comprehensive Organic Functional Group Transformations; Katritzky, A. R.; Meth-Conn, O.; Rees, C. W. Eds.; Pergamon: Oxford 1995; pp 617-618.

4. Capdevielle, P.; Lavigne, A.; Maumy M. Synthesis 1989, 451.

5. Kumar, H. M. S.; Reddy, B. V. S.; Reddy, P. T.; Yadav, J. S. Synthesis 1999, 586.

6. Das, B.; Madhusudhan, P.; Venkataiah B. Chem. Lett. 2003, 32, 738 and references cited therein.

7. Chen, F. E.; Fu, H.; Meng, G.; Cheng, Y.; Lü Y. X. Synthesis 2000, 1519. 
8. Lai, G.; Bhamare, N. K.; Anderson, W. K. Synlett 2001, 2, 230.

9. Nishiyama, K.; Oba, M.; Watanabe Tetrahedron 1987, 43, 693.

10. Elmorsy, S. S.; E.-Ahl, A.-A. S.; Soliman, H.; Amer F. A. Tetrahedron Lett. 1995, 36, 2639.

11. Suziki, H.; Nakaya, C. Synthesis 1992, 641.

12. Wang, E.-C; Lin G.-J. Tetrahedron Lett. 1998, 39, 4047.

13. Erman, M.B.; Snow, J.W.; Williams M.J. Tetrahedron Lett. 2000, 41, 6749.

14. Talukdar, S.; Hsu, J.-L.; Chou, T-C.; Fang J-M. Tetrahedron Lett. 2001, 42, 1103.

15. Shie, J.-J.; Fang, J-M. J. Org.Chem. 2003, 68,1158.

16. Shie, J.-J.; Fang, J-M. J. Org.Chem. 2007, 72, 3141.

17. Bandgar, B.P.; Makone S.S. Synth. Commun. 2006, 36, 1347.

18. Arote, N. D.; Bhalerao, D. S.; Akamanchi K. G. Tetrahedron Lett. 2007, 48, 3651.

19. Telvekar, V.N.; Patel, K.N.; Kundaikar, H.S.; Chaudhari, H. K. Tetrahedron Lett. 2008, 49, 2213.

20. Varvoglis, A. Hypervalent Iodine in Organic Synthesis; Academic Press: London, 1997.

21. Wirth, T.; Hirt U. H. Synthesis 1999, 1271.

22. Ladziata, U.; Zhdankin, V. V. Arkivoc 2006, (ix), 26.

23. Zhdankin, V. V. Arkivoc 2009, (i), 1.

24. (a) Supsana, P.; Liaskopoulos, T.; Tsoungas, P. G.; Varvounis, G. Synlett 2007, 17, 2671. (b) Rutan, K. J.; Heldrich, F. J.; Borges, L. F. J. Org. Chem. 1996, 60, 2948. (c) Coskun, N.; Ankan, N. Tetrahedron 1999, 55, 11943. (d) Hauser, C.R.; Jordan, E., J. Am. Chem. Soc. 1936, 58, 1772 (e) Furukawa, N.; Fukumura, M.; Akasaka, T.; Yoshimura, T.; Oae, S. Tetrahedron Lett. 1980, 21, 761. (f) Vaccari, D.; Davoli, P.; Spaggiari, A.; Prati, F. Synlett 2008, 9, 1317. (g) Hiegel, G.A.; Lewis, J.C.; Bae, J.W. Syn. Commun. 2004, 34, 3449. (h) Wang, B-L; Li, Z-M; Li, Y-H; Wang, S-H. Gaodeng Xuexiao Huaxue Xuebao. 2008, $29,90$. (i) Lebreton, L.; Curet, O.; Gueddari, S.; Mazouz, F.; Bernard, S.; Burstein, C.; Milcent, R. J. Med. Chem. 1995, 38, 4786. 